Proceedings of SPIE Conference on Remote Sensing of the Ocean and Sea Ice, Barcelona, Spain September 8-12, 2003

\title{
Observed Rossby Waves in the South China Sea From Satellite Altimetry Data
}

\author{
Peter C. Chu, and Chin-Lung Fang \\ Naval Ocean Analysis and Prediction Laboratory, Department of Oceanography \\ Naval Postgraduate School, Monterey, CA 93943, USA
}

\begin{abstract}
A global daily altimetry dataset was recently established at the Naval Research Laboratory on the base of Geosat Follow-On, TOPEX/POSEIDON, and ERS-2 data using the Modular Ocean Data Assimilation System (MODAS). After quality control such as tidal and orbit error removal, referencing to a consistent mean, it provides a global sea surface height (SSH) data with high temporal and spatial resolutions. We identify the first baroclinic Rossby waves with a phase speed around 3-5 cm/s in the northern South China Sea using 1994-2001 daily SSH data. We also find that there is no evident Rossby wave signal in the southern South China Sea.
\end{abstract}

Keywords: Rossby waves, South China Sea, TOPEX/POSEIDON/ERS-2 altimetry, Modular Ocean Data Assimilation System

\section{INTRODUCTION}

Rossby wave is an important component in large-scale ocean dynamics. After the launch of the TOPEX/ POSEIDON (T/P) satellite in August 1992 into a 10 day repeating orbit cycle, it is possible to derive information on baroclinic Rossby waves from the T/P altimeter data. Chelton and Schlax (1996) removed longitudinally coherent sea level signals associated with the steric effects of heating and cooling from the raw TOPEX/ POSEIDON (T/P) satellite altimetry data to get the global Rossby wave propagation signals. Their work has spurred oceanographers' interest in studying oceanic baroclinic Rossby waves (Witter and Gordon, 1999; and Cipollini et al., 1997). Cipollini et al. (1997) used the zonal gradient of sea surface height anomalies to remove the large-scale seasonal steric signal. Cipollini et al. (2001) further detected Rossby waves using 3D Radon Transform. The other methods are also used for wave detection such as the Fourier Transform (LeTraon and Minster, 1993), 2D Radon Transform (Hill and Robinson, 2000), complex sigular value decomposition (Susanto et al., 1998).

The detection of the Rossby waves from the satellite data up until now is mostly for ocean basins not for regional seas. Is there any possibility to detect the Rossby waves for the regional seas such as the largest marginal sea - the South China Sea? The South China Sea (SCS) is a semi-enclosed tropical sea located between the Asian land mass to the north and west, the Philippine Islands to the east, Borneo to the southeast, and Indonesia to the south (Fig. 1), a total area of $3.5 \square 10^{6} \mathrm{~km}^{2}$. It connects to the East China Sea (through Taiwan Strait), the Pacific Ocean (through Luzon Strait), the Sulu Sea, the Java Sea (through Gasper and Karimata Straits), and to the Indian Ocean (through the Strait of Malacca). All of these straits are shallow except Luzon Strait whose maximum depth is $1800 \mathrm{~m}$. The elliptical shaped central deep basin is $1900 \mathrm{~km}$ along its major axis (northeast-southwest) and approximately $1100 \mathrm{~km}$ along its minor axis, and extends to over $4000 \mathrm{~m}$ deep. 
The SCS is under the influence of monsoon winds and synoptic systems such as fronts and tropical cyclones. From November to March, the northeasterly winter monsoon winds correspond to monthly mean January 2000 wind speeds of near $10 \mathrm{~m} / \mathrm{s}$ for the whole SCS (Fig. 2a). From April to August, the southwesterly summer monsoon winds result in a monthly mean July 2000 wind speeds of approximate 8 $\mathrm{m} / \mathrm{s}$ in the Southern SCS and $4 \mathrm{~m} / \mathrm{s}$ in the northern SCS (Fig. 2b). The monthly mean winds (Fig. 2) are typical for monsoon winds. Highly variable winds and surface currents are observed during the transitional periods (Chu et al., 1997, 1999; Chu and Li, 2000). Moreover, synoptic systems often pass by the SCS and causes temporally and spatially varying wind fields. The highly variable wind systems and complicated topography make SCS a perfect location for the Rossby wave detection using the satellite data.

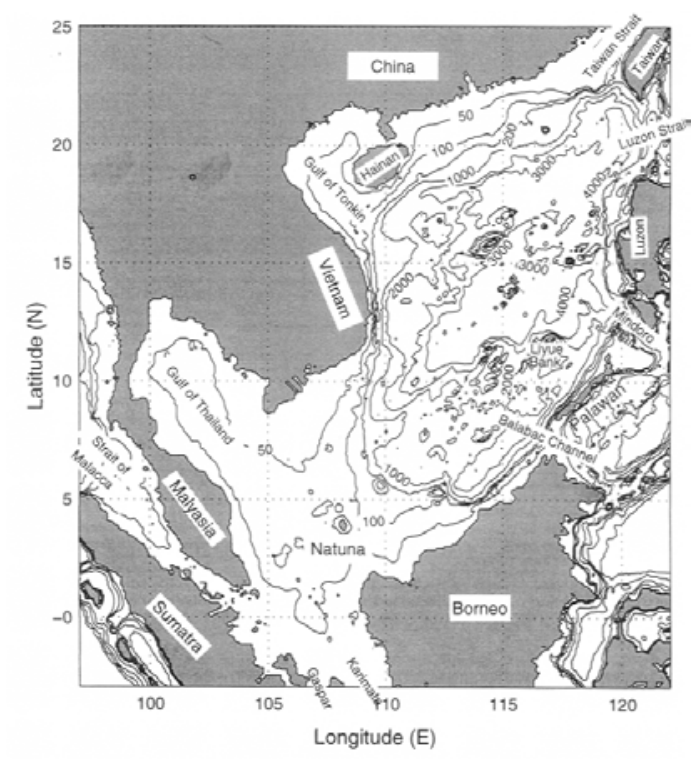

Figure 1. Geography and isobaths showing the bottom topography of the South China Sea.
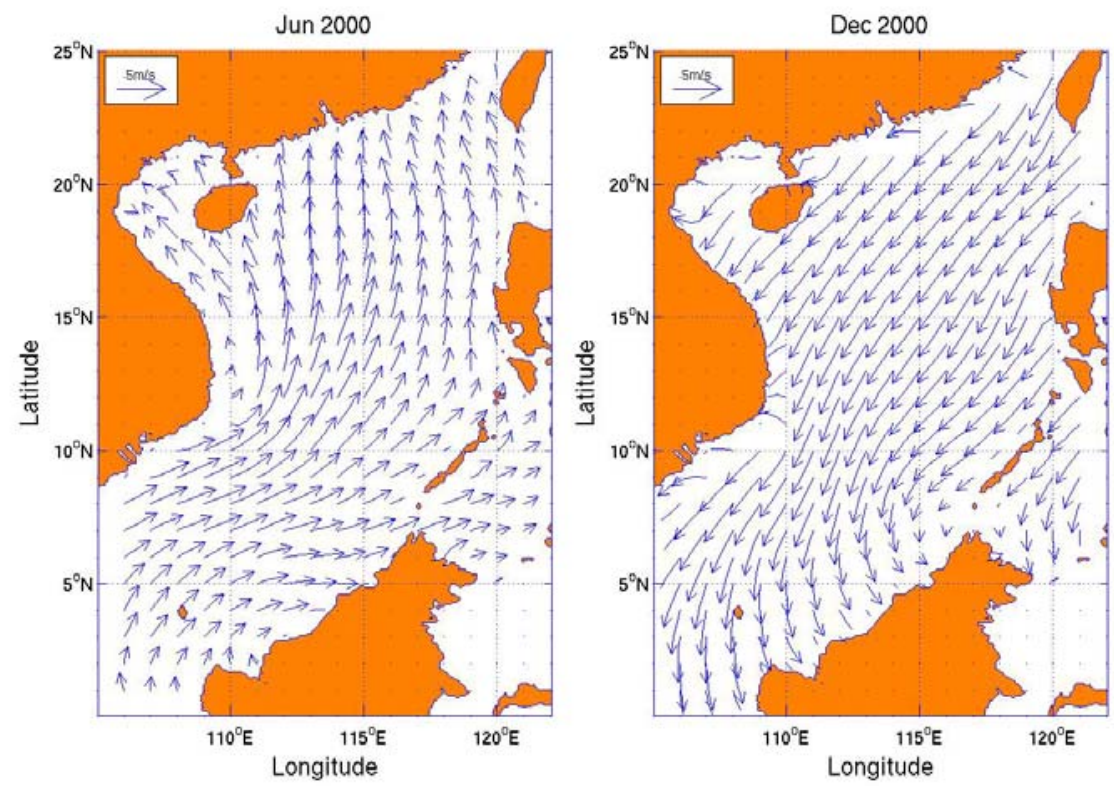

Fig. 2. Monthly mean wind speed at $10 \mathrm{~m}$ height computed from the QSCAT data: (a) January 2000, and (b) July 2000. 


\section{T/P DATA}

The T/P satellite, jointly launched by NASA and the French Space Agency, the Center National d'Etudes Spatiales (CNES) in August 1992, carried a state-of-the-art radar altimetry system (Fu et al. 1994). In addition to precise measurements of the distance between the satellite and the surface, SWH was derived from the shape of the leading edge of the returning radar pulse. The accuracy of SWH measurement by T/P was within the accuracy of the Geosat measurements (Callahan et al. 1994), i.e., $10 \%$ or $0.5 \mathrm{~m}$, whichever is greater (Dobson et al. 1987). T/P was maneuvered into a 9.9156-day repeat period during which two T/P sea surface height data are available at each crossover point (Fig. 3a). Time series of sea surface height at 4 passes $(051,229,152,190)$ are shown in Fig. 3b (taken 2000 as an example).
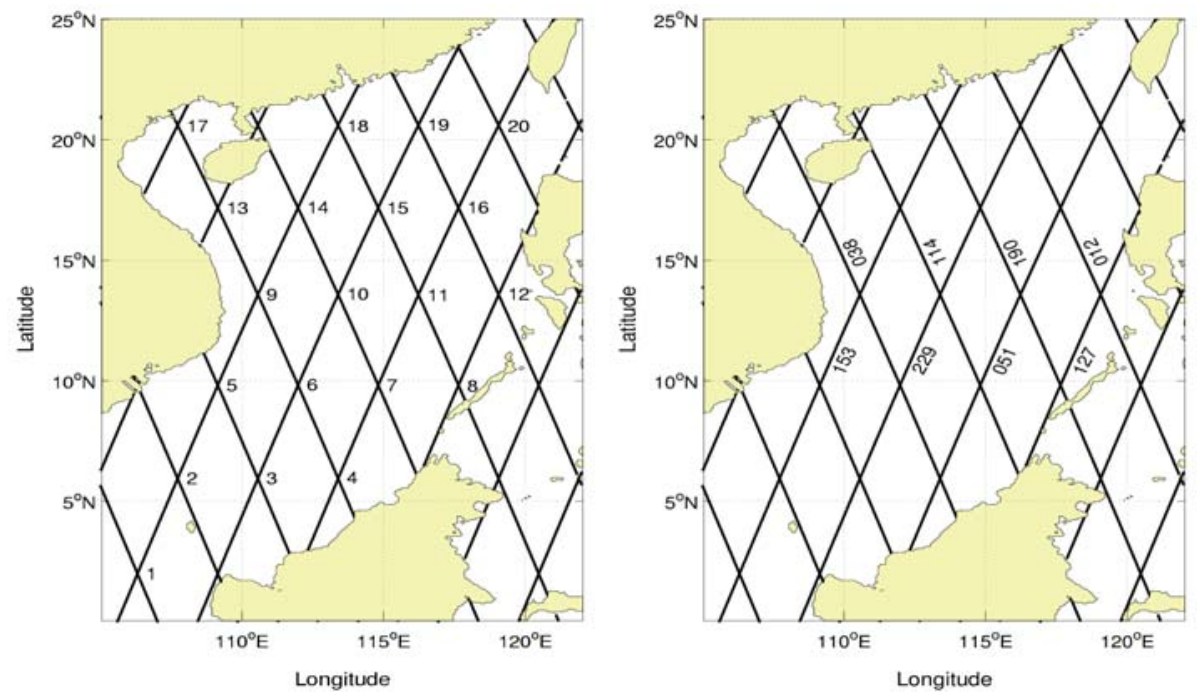

Fig. 3. T/P (a) crossover points and (b) tracks in the SCS.

\section{THE NAVY'S MODULAR OCEAN DATA ASSIMILATION SYSTEM}

The Modular Ocean Data Assimilation System (MODAS), recently developed at the Naval Research Laboratory, is a tool for using climatological and real-time data including satellite altimetry data and predominately used by the U.S. Navy (Fox et al., 2002). The analysis uses an optimal interpolation (OI) data assimilation technique that combines remotely sensed sea surface height anomaly and sea surface temperature data with other local observations from ships, aircrafts, or buoys to produce 2D sea surface height ( $\mathrm{SSH}$ ) data and 3D temperature, salinity, and sound speed data. The horizontal grid spacing for the MODAS-SCS is $1 / 4^{\circ}$. The MODAS interpolated SSH data (1993-1999) show different temporal-spatial variability pattern. Time-longitude cross-sections of SSH show evident westward propagation (i.e., the Rossby wave propagation) at $20^{\circ} \mathrm{N}$ (Fig. $4 \mathrm{a}$ ), $17^{\circ} \mathrm{N}$ (Fig. 4b), and $15^{\circ} \mathrm{N}$ (Fig. 4c) and evident seasonal variation with no westward propagation at $10^{\circ} \mathrm{N}$ (Fig. 4c) that implies that the westward propagating signals are detected only in the northern SCS (north of $15^{\circ} \mathrm{N}$ ) not in the southern SCS (south of $15^{\circ} \mathrm{N}$ ). The phase speed is estimated by $0.05-0.08 \mathrm{~m} \mathrm{~s}^{-1}$. The Rossby wave signal can be further analyzed using the complex empirical orthogonal function (CEOF) analysis. 

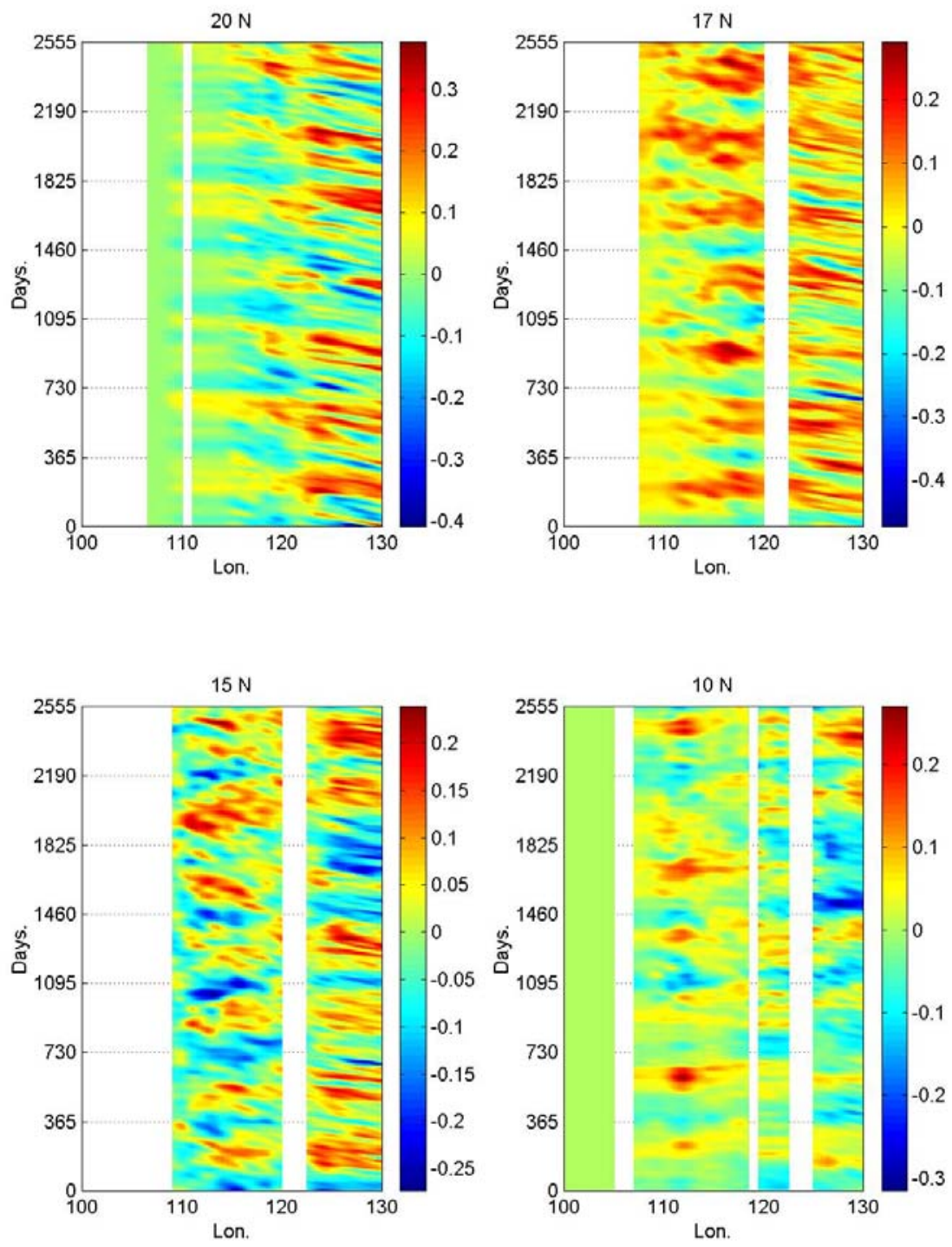

Fig. 4. SSH variation as a function of longitude and time along (a) $20^{\circ} \mathrm{N}$, (b) $17^{\circ} \mathrm{N}$, (c) $15^{\circ} \mathrm{N}$, and (d) $10^{\circ} \mathrm{N}$. Here, Day-0 and Day-2555 represent January 1, 1993 and the end of 1999, respectively.

\section{CEOF ANALYSIS}

Decomposition into CEOFs allows one to sort out by decreasing variance, spatial structures that propagate in space and vary in time (e.g., Barnett, 1983). Denote a temporally varying SSH data by $h(x, y, t)$ where $(\mathrm{x}, \mathrm{y})$ indicates spatial position and $\mathrm{t}$ is time. Denote a complex data field by $H(x, y, t)$, the real part of $H$ 
is the original data, $h$, and the imaginary part is the Hilbert transform of $h$. The latter is the data field phase advanced by $\pi / 2$ in time. When the data field $h(x, y, t)$ is expanded into the Fourier series,

$$
h(x, y, t)=\sum_{\omega}[a(x, y, \omega) \cos \omega t+b(x, y, \omega) \sin \omega t],
$$

then the Hilbert transformation $h_{t}(x, y, t)$ is represented by

$$
h_{t}(x, y, t)=\sum_{\omega}[b(x, y, \omega) \cos \omega t-a(x, y, \omega) \sin \omega t] .
$$

Then the complex data field $H(x, y, t)$ is represented by

$$
H(x, y, t)=h(x, y, t)+i h_{t}(x, y, t), \quad i \equiv \sqrt{-1} .
$$

The covariance matrix of $H$ is Hermitian and positive definite by construction. It has real positive eigenvalues $\lambda_{n}$ and corresponding complex eigenvectors $s_{n}(x, y)$. Hence, the complex data field $H(x, y, \mathrm{t})$ is represented by

$$
H(x, y, t)=\sum_{n} P C_{n}(t) s_{n}^{*}(x, y),
$$

where the asterisk implies complex conjugate. The functions $s_{n}(x, y)$ are referred as the spatial functions. . The principal components $P C_{n}(t)$ are computed by

$$
P C_{n}(t)=\sum_{x, y} H(x, y, t) s_{n}(x, y),
$$

that is referred as the temporal functions. Thus, the CEOF analysis provides maps of amplitude $A_{n}(x, y)$ and phase $P_{n}(x, y)$ with the time varying amplitude $a_{n}(t)$ and phase $p_{n}(t)$. For each mode $n$, the characteristics in frequency and wavenumber vector of the propagating signal are given by the slope of the temporal phase $d p_{n} / d t$ and by the spatial gradient of the phase vector $\left(\left(\partial P_{n} / \partial x, \partial P_{n} / \partial y\right)\right.$.

\section{Principle CEOF Modes}

We perform a CEOF analysis using the method outlined in Section 4 and obtain the first five leading CEOFs, which are able to account for almost $80.83 \%$ of the total variance during the seasons (Table 1). When combined CEOF1 and CEOF2 explain $58.74 \%$ of the total variance. Each CEOF mode is normalized so that its total spatial variance is equal to unity. So, those patterns of the first two CEOFs are enough to explain the temporal-spatial SSH variability of the whole SCS. Hence, it suffices to focus on the first two CEOFs.

Table 1. Variances of the First Five Leading CEOFs

\begin{tabular}{|l|l|l|}
\hline CEOF & Variance (\%) & $\begin{array}{l}\text { Cumulative } \\
\text { Variance (\%) }\end{array}$ \\
\hline 1 & 42.25 & 42.25 \\
\hline 2 & 16.49 & 58.74 \\
\hline 3 & 8.84 & 67.58 \\
\hline 4 & 7.87 & 75.39 \\
\hline 5 & 5.44 & 80.83 \\
\hline
\end{tabular}




\subsection{CEOF1 - Seasonal Variability}

CEOF1 accounts for $42.25 \%$ of the total variability. The left panels of Fig. 5 show the spatial structure (upper panel) and temporal (lower panel) variability of the amplitude $\left[A_{1}(x, y), a_{1}(t)\right]$, and the right panels of Fig. 5 show the spatial structure (upper panel) and temporal variability (lower panel) of the phase $\left[P_{1}(x\right.$, $\left.y), \quad p_{1}(t)\right]$. The time series of $p_{1}(t)$ indicates an annual frequency. The seasonal variability varies horizontally [i.e., $A_{1}(x, y)$ ] and is larger in the northern SCS than in the southern SCS with strongest signal occurring from Luzon Strait to the central SCS at $15^{\circ} \mathrm{N}$ (upper left panel). The amplitude varies temporally $\left[a_{1}(t)\right]$ and has a maximum value $\left[a_{1}(t)=4.2\right]$ in November 1994 and a minimum value $\left[a_{1}(t)=1.5\right]$ in March 1998. The coincidence of minimum value of $a_{1}(t)$ and 1997-1998 El Nino event may suggest the connection between the weak SCS seasonal variability to the El Nino event.
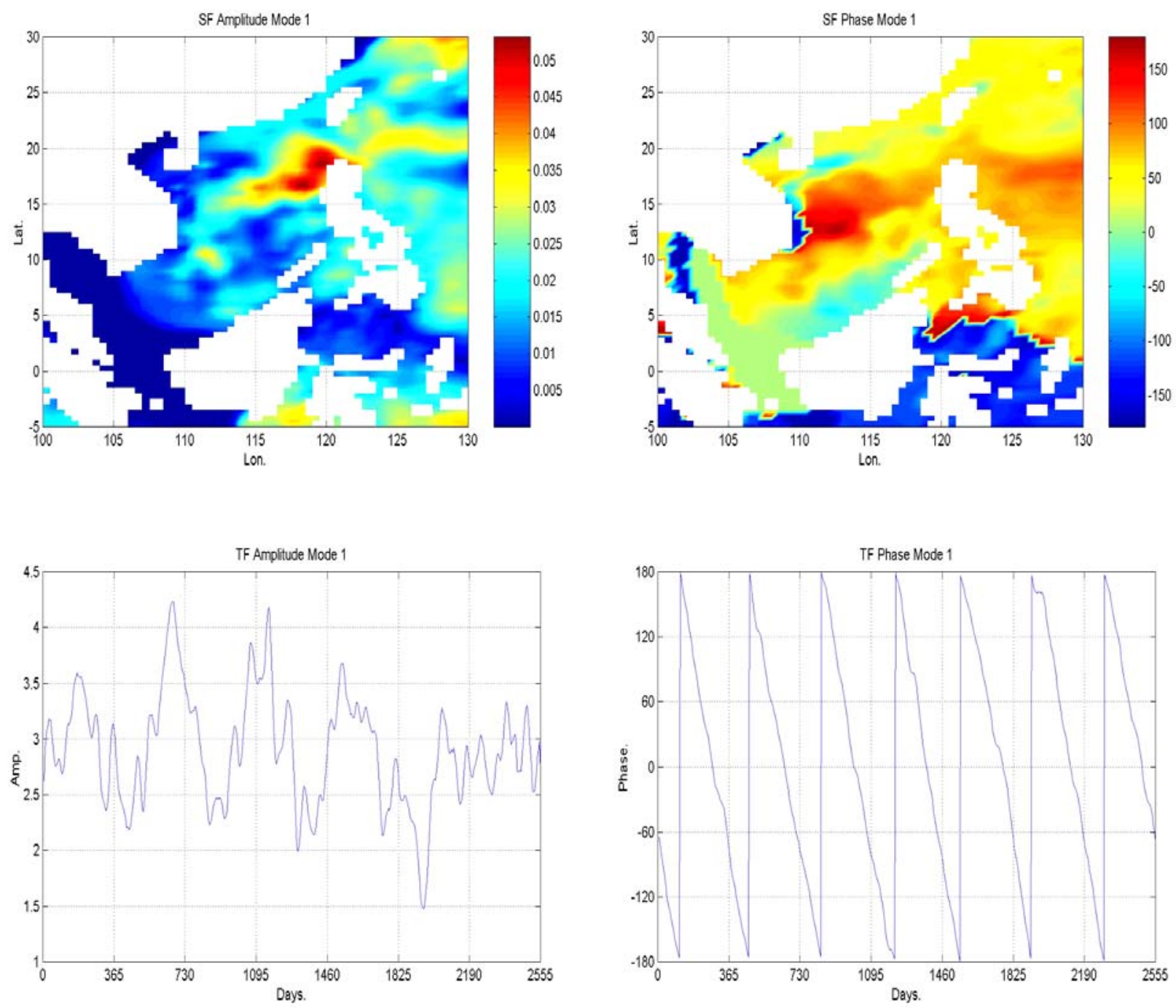
Fig. 5. Spatial (upper panels) and temporal (lower panels) variability of the amplitude (left panels) and phase angle (right panels) of CEOF1. Here, Day-0 and Day-2555 represent January 1, 1993 and the end of 1999, respectively.

\subsection{CEOF2 - Wave Signals}

CEOF2 accounts for $16.49 \%$ of the total variability. The left panels of Fig. 6 show the spatial structure (upper panel) and temporal (lower panel) variability of the amplitude $\left[A_{2}(x, y), a_{2}(t)\right]$, and the right panels of Fig. 6 show the spatial structure (upper panel) and temporal variability (lower panel) of the phase $\left[P_{2}(x\right.$, $\left.y), \quad p_{2}(t)\right]$. The time series of $p_{2}(t)$ indicates combined intraseasonal and interannual frequencies. The interannual frequency occurs from April 1994 to December 1995, and from April 1996 to December 1998.

The intraseasonal frequency occurs during the rest of periods. Strong gradient $\partial P_{2} / \partial y$ in the northern SCS between $16^{\circ} \mathrm{N}-20^{\circ} \mathrm{N}$ clearly indicates a dominant westward propagation from the western Pacific Ocean to the SCS. The horizontal map of the amplitude $A_{2}(x, y)$ shows larger values in the western Pacific than in the SCS. This indicates that the Rossby waves weakens as they are propagated into the SCS. The amplitude varies temporally $\left[a_{2}(t)\right]$ and has a maximum value $\left[a_{1}(t)=4.0\right]$ in March 1998. The coincidence of maximum value of $a_{2}(t)$ and 1997-1998 El Nino event may suggest the connection between the strong Rossby wave signal to the El Nino event.
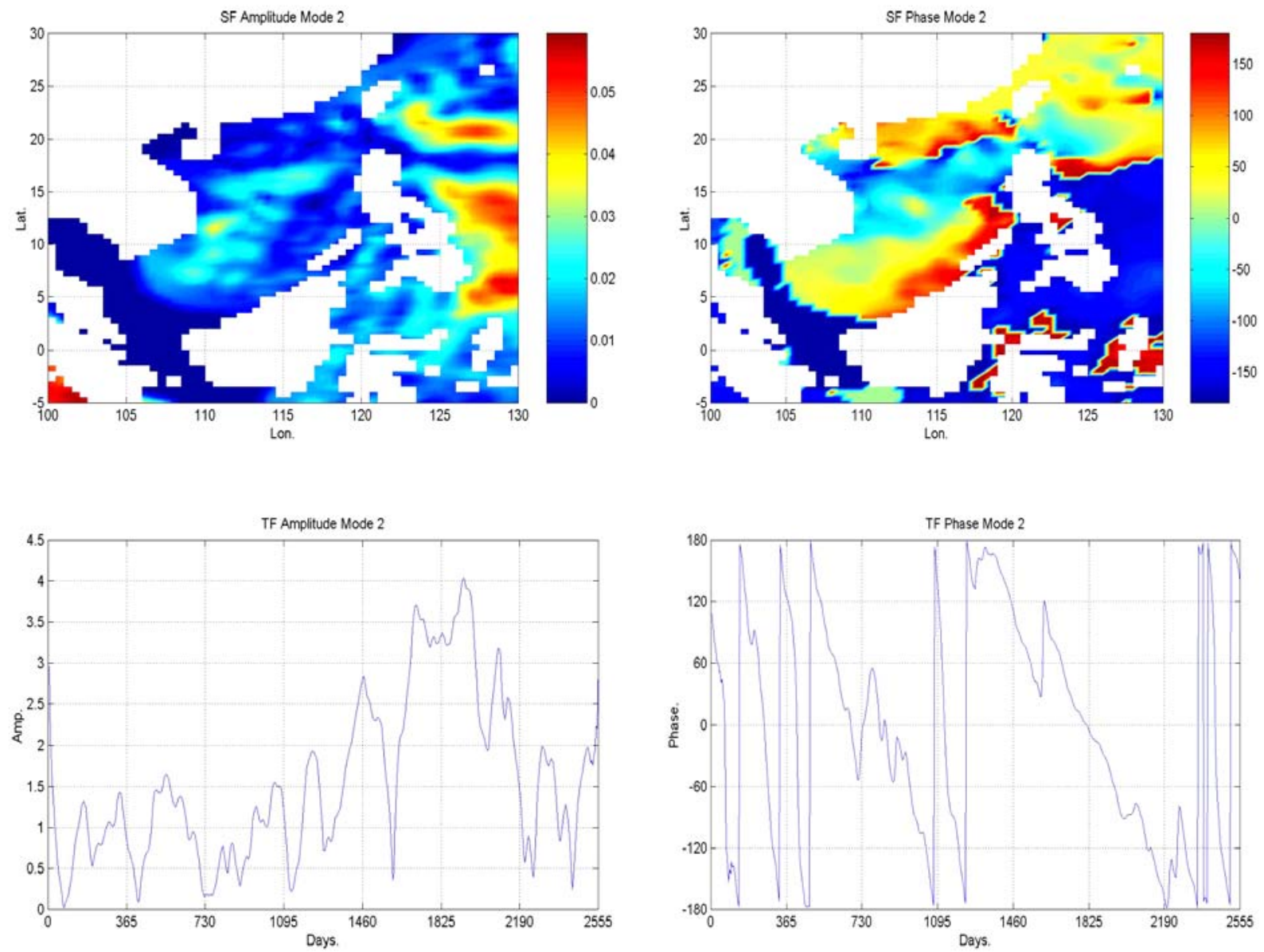

Fig. 6. Spatial (upper panels) and temporal (lower panels) variability of the amplitude (left panels) and phase angle (right panels) of CEOF2. Here, Day-0 and Day-2555 represent January 1, 1993 and the end of 1999, respectively. 


\section{CONCLUSIONS}

The CEOF analysis was used to analyze interpolated daily T/P altimetry data in the South China Sea to investigate the spatial and temporal variability of SSHA. Our study shows the existence of multi-time scale variability: seasonal, interannual, and intraseasonal. Following results were obtained.

(1) The seasonal signal accounts for $42.25 \%$ of the total variability. The seasonal variability is larger in the northern SCS than in the southern SCS with strongest signal occurring from Luzon Strait to the central SCS at $15^{\circ} \mathrm{N}$. The seasonal amplitude varies temporally and is strongest in November 1994 and weakest in March 1998. The weakest seasonal signal coincides with 1997-1998 El Nino that may suggest the connection between the weak SCS seasonal variability to the El Nino event.

(2) The interannual and intraseasonal variability accounts for $16.49 \%$ of the total variability. The interannual frequency occurs from April 1994 to December 1995, and from April 1996 to December 1998. The intraseasonal frequency occurs during the rest of periods. The Rossby waves are propagating and weakening from the western Pacific into the northern SCS (between $16^{\circ} \mathrm{N}-20^{\circ} \mathrm{N}$ ). The strong Rossby wave signal may be connected to the El Nino event.

(3) The westward propagating Rossby wave signals are detected only in the northern SCS (north of $15^{\circ} \mathrm{N}$ ) not in the southern SCS (south of $15^{\circ} \mathrm{N}$ ). The phase speed is estimated by $0.05-0.08 \mathrm{~m} \mathrm{~s}^{-1}$.

\section{ACKNOWLEDGMENTS}

Authors are grateful to Chenwu Fan for programming assistance. This work was funded by the Naval Oceanographic Office, and the Naval Postgraduate School.

\section{REFERENCES}

Chu, P.C., H. C. Tseng, C.P. Chang, and J.M. Chen, South China Sea warm pool detected in spring from the Navy's Master Oceanographic Observational Data Set (MOODS). J. Geophys. Res., 102, 15,76115,771, 1997.

Chu, P.C., N.L. Edmons, and C.W. Fan, Dynamical mechanisms for the South China Sea seasonal circulation and thermohaline variabilities. J. Phys. Oceanogr., 29, 2971-2989, 1999.

Chu, P.C., and R.F. Li, 2000: South China Sea isopycnal surface circulations. J. Phys. Oceanogr., 30, 2419-2438.

Chelton, D.B., and M.G.Schlax, Global observation of oceanic Rossby waves, Science, 272, 234-238, 1996.

Cipollini P, D. Cromwell, M..S. .Jones et al., Concurrent altimeter and infrared observations and infrared observations of Rossby wave propagation near 34 degrees in the Northeast Atlantic. Geophys. Res. Lett., 24, 889-892, 1997.

Cipollini, P., D. Cromwell, P. G. Challenor and S Raffaglio, Rossby waves detected in global ocean colour data, Geophys. Res. Let., 28, 323-326, 2001.

Fox, D.N., W. J. Teague, C.N. Barron, M.R. Carnes, and C.M. Lee, The modular ocean data assimilation system (MODAS). J. Atmos. Oceanic Technol., 19, 240 - 252, 2002.

Hill, K.L., I. S. Robinson and P .Cipollini, Propagation characteristics of extratropical planetary waves observed in the ATSR global surface temperature record. J .Geophys.Res, 105, 21927-21 945, 2000.

Le Traon, P.Y and J.-F. Minster. Sea level Variability and Semiannual Rossby Waves in the South Atlantic Subtropical Gyre. J. Geophys. Res. 98, 1231-12326, 1993.

Quartly, G. D., P. Cipollini, D. Cromwell, P. G. Challenor, "Rossby waves: synergy in action", Phil. Trans. R. Soc. London A, 10.1098/rsta.2002.1108, 2003.

Susanto, R. D., Q. Zheng, and X._H. Yan, Complex singular value decomposition analysis of equatorial waves in the Pacific observed by TOPEX/POSEIDON altimeter. J. Atmos. Oceanic Technol., 15, 764-774, 1998. 
Witter, D.L, and A.L.Gordon, Interannual variability of South Atlantic circulation from 4 years of TOPEX/POSEIDON satellite altimeter observations, J.Geophys.Res., 104, 20927-20948, 1999. 